\title{
Stem Cell Treatment as Innovation in Sustaining Socio-Economic Condition in Health Care Sector in India
}

\section{Sheeraz Ahmad Alaie*}

Centre for Studies in Science, Technology and Innovation Policy, School of Social Sciences, Central University of Gujarat, Gujarat, India

\begin{abstract}
Stem cell research as a radical innovation in the medical field holds promises for good health and development as its treatment is curable to many diseases. The objectives of this paper is to explore the challenges and scope for establishing Stem Cell Research as one of the affordable branch of medicine in India and to examine whether Stem cell research would face the same ethical and religious hostility in the Indian context as faced by it in other parts of the globe. The methodology would involve the use of secondary data sources in order to understand the scenario of stem cell research in India, with respect to the aforementioned objectives. It is still an emerging field in India, which needs proper funding and good policies for implementation by government authorities and organizations like DST, DBT and ICMR. Several research institutions and biotech companies have been formed with the mandate on bringing stem cell research outcomes from bench to bedside.
\end{abstract}

Keywords: Stem cell; Innovation; Socio-economic condition; Methodology; Ethical; India

\section{Introduction}

The health is regulated by the health technologies because of its indulging conditions from the normal one due to some diseases. Day by day due to the science and technology, more health technologies come into field to control the diseases. One of such health technologies is the stem cell related technologies which had made a radical innovation in the health sectorial system. Till present lot of resources had been invested on this and it is also making great success in controlling various diseases. In this paper stem cell research (SCR) has been considered. The research study is qualitative in nature. The secondary data related to the innovation, health sector and SCR have been used to understand the research problem. The paper attempts to understand the problems and prospects regarding the SCR in perspective of innovation. As this field is new to the medical sciences, it can be considered as the innovation to such sector. In order to improve and develop such technologies research, funding and human resources is required. Within the innovation systems, there exist the actors, institutions, and interactions within them. These are responsible for the proper and systemic functioning of the system, by research and development, funding and law making perspectives. If the regulatory bodies are investing so much in this field, what about the future, could it face the ethical or religious problems? As it is seen in some countries that it had been made a debate as per socioethical views are considered. Regarding the marketing and economic status it is to be pointed out whether a common man can afford such kind of facility or not? Would this facility be provided to the general public? India is still in the list of the developing countries where most of the people do not know about the health and health technologies; it needs to aware them about all this. Government should also provide some subsidizing schemes in application of such technologies so that most of the people can get this facility.

\section{Innovation and health technologies}

In order to understand the health technologies especially SCR within the perspective of innovation system, it needs to be conceptualized in innovation systemic framework. The evolution of innovation is concerned with the work of Schumpeter, when he combined the concepts from sociology, economics and history into another tactics to study the socio-economic change focusing on innovation. His major theoretical approach on the subject, 'The theory of economic development', published in German in 1912, focused in particular on the interaction between innovative individuals, what he called 'entrepreneurs', and their inert social surroundings, while later works extended the approach to also take into account organized $\mathrm{R}$ and $\mathrm{D}$ (research and development) activities in large firms [1]. An important event was the formation of the Science Policy Research Unit (SPRU) at the University of Sussex in 1966 with Christopher Freeman as its first Director. The human resources were multidisciplinary there from various subjects like sociology, economics, engineering and psychology, which shows the vast scope of the innovation policy studies. Innovation defined as the introduction of novelties' or 'the alteration of what is established by the introduction of new elements or forms'. Lundvall defined it as, the elements and relationships which interact in the production, diffusion and use of new, and economically useful, knowledge and are either located within or rooted inside the borders of a nation state [2]. Nelson defined it as a set of institutions whose interactions determine the innovative performance of national firms [3].

Patel and Pavitt defined it as, the national institutions, their incentive structures and their competencies that determine the rate and direction of technological learning (or the volume and composition of change generating activities) in a country [4]. These concepts given by the authors related to the innovation studies help to frame the SCR in health system as a relevant process and radical innovation. Science, technology, invention and innovation are the key factors for the development of a nation in every field. These all under the policies faith on the assumption they will facilitate overall development and

*Corresponding author: Sheeraz Ahmad Alaie, Research Scholar, Centre for Studies in Science, Technology and Innovation Policy, School of Social Sciences, Central University of Gujarat, Sector 30, Gandhinagar, Gujarat-382030, India, Tel: +918488967953; E-mail: elahisheeraz10@gmail.com

Received July 24, 2014; Accepted March 02, 2015; Published March 04, 2015

Citation: Alaie SA (2015) Stem Cell Treatment as Innovation in Sustaining SocioEconomic Condition in Health Care Sector in India. J Stem Cell Res Ther 5: 269 doi:10.4172/2157-7633.1000269

Copyright: (C) 2015 Alaie SA, et al. This is an open-access article distributed under the terms of the Creative Commons Attribution License, which permits unrestricted use, distribution, and reproduction in any medium, provided the original author and source are credited. 
contribute to the improvement of living standards and the quality of life of the people. Health is an important component of the developmental process. It is an adage that "health is wealth" which means healthy nation can make wealthy nation. Health is a state of complete physical, mental and social well-being and not merely the absence of disease or infirmity (WHO). It is a pathway to development as well as a fruit of it. The health of a country depends mostly on the quality and reach of the health system and the support provided by the research system related to health to respond to health related problems and challenges.

\section{Health Facilitation and Policies}

Progress has been made but time lags in translating research outcomes into applicable health products or knowledge application generated through research. Important is to ensure that the health research products should reach and must be used for and by the people who need it most. Health research should be directed to be used to develop drugs, diagnostics, devices, and vaccines which should find place in the health systems of the country. The interaction between research communities, firms, industries, and government authorities is the only way to facilitate it. As per the concept of market innovation, it refers to the new knowledge embodied in distribution channels, product, applications, as well as customer expectations, preferences, needs, and wants [5]. The main idea is the improvement of the components of the marketing mix, that is, product, price, promotion and place [6]. The Frascati Manual (2004) specifies that market innovation concerns marketing of new products and covers activities in connection with the launching of a new product. These activities may include market tests, adaptation of the product for different markets and launch advertising, but exclude the building of distribution networks for market innovations.

The planning commission of India had constituted a working group on Health systems Research, Biomedical Research and Development and regulation of Drugs and Therapeutics for the 11th five year plan vide its order No.2 (110/2006-H\&FW of May 25, 2006) regarding this aspect [7]. Exchange of biological material will be permitted as per existing procedures of funding agencies (DST, DBT, ICMR) or the Health Ministry's screening committee (as per Government of India guidelines), even if no funding is involved after the joint proposal with appropriate MOU is approved by National Apex Committee for Stem Cell Research and Therapy (NACSCR). The working group established by planning commission reviewed the present position, progress and problems in basic, clinical, applied and operational studies in biomedical research during the 10th plan period. The major achievements in areas of health research of the Indian Council of Medical Research (ICMR), Council of Scientific and Industrial Research (CSIR), Department of Biotechnology (DBT) and Department of Science and Technology (DST) were reviewed in the backdrop of the planning commission thrust areas of the 10th plan period. This group has already highlighted the main problems in the current state of health and biomedical research in the country which are given as under:-Absence of a national health research policy
i. Weak health research system
ii. Negligence of health systems research
iii. Inadequate capacity to plan and implement
iv. Lacks monitoring and evaluation system
v. Priority setting not done on accepted scientific principles
vi. Inadequate funds for health and in turn for health research

vii. Narrow research base in medical colleges and other institutes

viii. Lack of policy, plan or management of human resources development for health research

ix. Neglect of translational research

X. Not so strong inter agency collaborations

xi. Limited access and utilization of health research information.

Source: Healthcare: Eleventh Five Year Plan (2007-2012).

\section{Stem cell research in health system}

Stem cell research system is a type of radical innovation system which has limited the usage of some pharmaceuticals. Many diseases like neurodegenerative (Alzheimer's, Parkinson's) diseases, cardiovascular diseases, diabetes, strokes, burns, epithelial diseases, retinal problems are such challenging diseases which became curable by stem cell applications [8]. This research uses the human stem cells as the element for treatment. Stem cells are defined functionally as cells that have the capacity to self-renew as well as the ability to generate differentiated cells [9]. Stem cell research is both an evolution and a revolution in modern biomedicine. It is new as its discovery dates to November of 1998 when Dr. James Thompson along with other researchers at University of Wisconsin, first reported that they had successfully isolated human embryonic stem cells. Once researchers isolate stem cells and allow them to proliferate in a culture for six or more months without differentiating, a stem cell line has been created [10].

\section{Types of stem cells used in SCR}

Based on the sources of getting the stem cells are human embryos, adults and umbilical cord, these cells are respectively called as embryonic stem cells, adult stem cells and cord blood stem cells. The human embryonic stem cell is the parent of all other cell types in body and is derived from the embryonic stage of human being which is in the form of ball shaped 'blastocyst'. The process of cleavage of zygote forms blastocyst after four days of fertilization (Scott F. Gilbert and Anne M. Raunio, Editors Embryology, Constructing the Organism 1997 Sinauer Associates, Inc., Sunderland, MA). It has an outer layer of cells while inside it has a hollow sphere with a cluster of cells called the inner cell mass. These inner mass cells are pluripotent in nature and may undergo further specialization into stem cells and give birth to cells having a particular function. These cells have the capability to turn into different types of tissues in the human body. Adult stem cells are used for both allogenic and autogenic therapeutically uses. These cells may be derived from the bone marrow, peripheral blood, tissues, muscles, cardiac tissues, cartilage, brain tissues, etc.

The adult stem cells are hematopoietic, non-hematopoietic and organ specific stem cells. Non-hematopoietic stem cells are mesenchyme stem cells (MSCs) and are present in any tissues of adult cells, i.e. bone marrow, cord blood, fat, bone, placenta, lung and liver. These cells are pluripotent i.e. can differentiate into several cell lineages such as cartilage, bone, active tissues, etc. to treat various diseases. Because of these unique characteristics, MSCs possess enormous potential for allogenic transplantation (Stem cells and the future of regenerative medicine, 2002). The third source for getting stem cells is the umbilical cord blood as it is the richest source of stem cells. Umbilical cord has the function only inside the mother's womb for embryo. New-born infants no longer need their umbilical cords, so they have traditionally been discarded as a by-product of birth process. In recent years, however cord derived stem cells has proven useful in treating the same type of 
health problems as those treated, using bone marrow and peripheral blood stem cells (Umbilical Cord Blood: The Future of Stem Cell Research? Erica Lloy; for National Geographic News, April 6, 2006). UC blood stem cell transplants are less prone to rejection as they lack well developed immune system. In the present time most focus is driven on Induced pluripotent stem cells (iPS) and mesenchymal stem cells (MSCs) [11].

Induced pluripotent stem cells: An induced pluripotent stem cell is a cell taken from any tissue from a child or adult that has been genetically improved to behave like an embryonic stem cell, having ability to form all adult cell types [12]. In 2006, Yamanaka made a ground breaking discovery that wins him the Nobel Prize in Physiology or Medicine just six years later. He reprogrammed the adult specialized cells to turn into stem cells that can make any type of cell hence called them induced pluripotent stem cells, or iPS cells.

Yamanaka used the genes of mouse cells for his experiments where he got success. Scientists can now also do this with human cells, by adding even fewer than four genes. IPS cells and embryonic stem cells are very similar [13]. They are self-renewing which can reproduce themselves indefinitely. Both iPS cells and embryonic stem cells can help us understand how specialized cells develop from pluripotent cells. These cells may provide an unlimited supply of replacement cells and tissues for many patients with currently untreatable diseases. In contrast to embryonic stem cells, making iPS cells doesn't depend on the use of cells from an early embryo. Current research specifies that some genes in iPS cells behave in a different way to those in embryonic stem cells. This is caused by incomplete reprogramming of the cells or genetic changes acquired by the iPS cells as they grow and multiply [14].

Future applications and challenges for iPS cells: Reprogramming holds great potential for new medical applications, such as cell replacement therapies. Since iPS cells can be made from a patient's own skin, they could be used to grow specialized cells that exactly match the patient and would not be rejected by the immune system (Euro stem cell, 2012). If the patient has a genetic disease, the genetic problem could be corrected in their iPS cells in the laboratory, and these repaired iPS cells used to produce a patient-specific batch of healthy specialized cells for transplantation. But this benefit remains theoretical for now (Euro stem cell, 2012). Until recently, making iPS cells involved everlasting genetic changes inside the cell, which can cause tumours to form. Scientists have now developed methods for making iPS cells without this genetic modification [15]. These new techniques are important steps towards making iPS-derived specialized cells that would be safe for use in patients. Further research is needed to comprehend fully how reprogramming works and how iPS cells can be controlled and produced steadily enough to meet the high quality and safety requirements for use in the clinic.

Mesenchymal stem cells: Mesenchymal stem cells (MSCs) are an example of tissue or adult stem cells. They are multipotent but not pluripotent meaning they can produce more than one type of specialized cell of the body, but not all types. MSCs make the different specialized cells found in the skeletal tissues. They can differentiate or specialize into cartilage cells, bone cells osteoblasts and fat cells. These specialized cells each have their own characteristic shapes, structures and functions, and each belongs to a particular tissue. MSCs were originally found in the bone marrow. There have been many claims that they also exist in a wide variety of other tissues, such as umbilical cord blood, adipose tissue and muscle. It has not yet been established whether the cells from these different tissues are really the same or similar to the mesenchymal stem cells of the bone marrow.
The bone marrow has many different types of cells. Among them are blood stem cells called hematopoietic stem cells (HSCs) and a variety of different types of cells belonging to a group called mesenchymal cells. Only about $0.001-0.01 \%$ of the cells in the bone marrow are MSCs. It is fairly easy to obtain a mixture of different mesenchymal cell types from adult bone marrow for research. But isolating the tiny fraction of cells that are mesenchymal stem cells is more complicated. Some of the cells may be able to form some tissues like bone or fat, but still do not have all the properties of mesenchymal stem cells. The challenge is to classify and pick out the cells that can both self-renew and can differentiate into three cell types - bone, cartilage and fat. Scientists working in such field have not yet reached an agreement about the best way to do this. Some of the important usages of MSCs which have proved beneficial in treatment of some diseases are given in the subsections below.

Bone and cartilage repair: The ability of MSCs to differentiate into bone cells called osteoblasts led to their use in early clinical trials investigating the safety of potential bone repair methods. These studies are looking at possible treatments for localized skeletal defects. Other research is focussed on using MSCs to repair cartilage if damaged by a sudden injury like a fall, or over a long period by a condition like osteoarthritis, a very painful disease of the joints. Cartilage cannot repair itself well after damage.

The best treatment available for severe cartilage damage is surgery to replace the injured joint with an artificial one. Because MSCs can differentiate into cartilage cells called chondrocytes, scientists hope MSCs could be injected into patients to repair and maintain the cartilage in their joints. Researchers are also investigating the possibility that transplanted MSCs may release substances that will tell the patient's own cells to repair the damage. Researchers are working on new techniques for transplanting the cells, such as developing threedimensional structures or scaffolds that counter the conditions in the part of the body where the cells are needed. These frameworks will hold the cells and encourage them to differentiate into the desired cell type.

Heart and blood vessel repair: Some studies in mice suggest that MSCs can promote formation of new blood vessels in a process called neovascularisation. MSCs do not make new blood vessel cells themselves, but they may help with neovascularisation in a number of ways. For example, they may release proteins that stimulate the growth of other cells called endothelial precursors - cells that develop to form the inner layer of blood vessels. Such studies on animals have led researchers to hope that MSCs may provide a way to repair the blood vessel damage connected to heart attacks or diseases such as critical limb ischaemia. A number of early stage clinical trials using MSCs in patients are currently underway but it is not yet clear whether the treatments will be effective [16].

Inflammatory and autoimmune diseases: Several claims have been made that MSCs are able to evade detection by the immune system and can be relocated from one patient to another without risk of immune rejection by the body. However, these claims have not been confirmed by other studies. It has also been suggested that MSCs may be able to slow down the multiplication of immune cells in the body to reduce inflammation and help treat transplant rejection or autoimmune diseases [17]. Again, this has yet to be proven and much more evidence is needed to establish whether MSCs could really be used for this kind of application.

Current research and the future: Research into therapies using MSCs is still in its infancy. A great deal more work is needed before such therapies can be used routinely in patients. Unique properties of 
stem cells include that they are unspecialized, or they have the potential to make many different types of cells, are capable of dividing and renewing themselves for long periods of time, and they can also turn into specialized cells. Unspecialized cells transform into specialized cells such as neurons, muscle cells, or red blood cells through a process known as differentiation. Hence their therapy is helpful in restoring cellular and organ function damaged by degeneration and various injuries. Stem cells are either harvested from adults or embryos, so they are either human adult or human embryonic stem cells. The growing of these cells isolated, outside the body requires cultural medium with right mixture of nutrients, hormones, growth factors, and blood serums. Undifferentiated cells are considered pluripotent when they have the potential to become any type of cell provided when the right conditions. In this paper the issue is whether the benefit of such scientific miracle would be affordable to all common people or not with perspective to India, what policies should be implemented by the actors and organizations in order to boost the research and development in this sectorial system.

\section{SCR basic and extensive research}

Stem cell research applications hold great promise for improving human health and cure many serious diseases which were incurable. Stem cells have been successfully derived from various sources and they are extensively used in basic research for the fundamental understanding of how cells multiply and differentiate to other cell types. Extensive basic research is required for standardization of methods for the isolation of embryonic and adult stem cells from various sources. Stem cells are very valuable materials used for the research and clinical treatments, so they need well and proper research techniques for their isolation and cultural processes [18]. It is still remembered the "Hwang Woo Suk's work" who wasted 2200 human eggs in his research which posed a huge ethical social issue in his now discredited stem cell research, it has obscured the greater problem of lack of respect for the embryo.

Clinical SCR procedures: Clinical trials using cells after major manipulation or those sponsored by multinationals involving stem cell products imported from abroad shall require prior approval of the NACSCR through IC-SCR (Institute committee for Stem Cell Research), IEC (Institutional Ethics Committee), DCGI (Drug Controller General of India) and respective funding agency as per its procedure/Health Ministry's Screening Committee (HMSC). The import of biological materials for research and development is regulated by GOI (F. No. L./950/53/97-H1 (Pt.) dated 19th Nov 1997). Import of approved and marketed 'drugs' (therapeutic products) from abroad requires license from the DCGI as per its Act and Rules. Clinical grade stem cells are also produced under GTP/GMP (Good Manufacturing Practices) conditions and these are used for drug discovery and drug screening research. They are also exploited for clinical research/trials for human disease. These procedures require approval of ICSCR/IEC and NAC (National Apex Committee)-SCR [19].

A NAC-SCR has been constituted to provide an oversight to all the IC-SCRs for achieving a uniform standard across the country. In addition, it will have the major role of reviewing, approving and monitoring of research categorized as restricted, after initial review and recommendation by the IC-SCR. A close co-operation and compliance by all the statutory bodies essential to achieve the desired goals [20]. Future prospects for embryonic stem cell research include the following: isolation of stem cells from healthy persons; proper culturing; generation of therapeutic grade cell lines; identification of human embryonic stem cells (hESC) growth factors; controlled differentiation, i.e. generation of specific cell population; study of fundamental changes in cell cycle control that occurs during embryonic stem cells differentiation; maintenance of stem cell in undifferentiated stage; regulation of differentiation of ESC; pluripotency and differentiation of established cell lines; standardization of animal free defined culture conditions; developmental potential of human versus mouse ESC; standardization in use of specific stem cells to specific organ systems. In addition, ESC could also be used for toxicology tests and may be valuable tools for traditional drug discovery.

\section{SCR Current socio-economic status in India}

Health sector considered as one of the most important sectors in India where investment is made very vastly. This sector includes various research universities, companies, firms, and laboratories; also the role of government is highly influential, as the sector mostly functions as formal in nature. Breschi and Malerba reported that sectoral innovation system (SIS) focuses on the group of firms related with the development and manufacturing of the products of a specific sector and to generate and utilise the technologies of that sector [4]. The main components of SIS are organizations and institutions. Organizations are players or actors which are formal structures created consciously and have an explicit purpose. Here also in health sector innovation system important organizations are universities, firms, venture capital organizations and responsible innovation policy making public agencies. Institutions are sets of common habits, routines, norms, rules, established practices or laws that are responsible for regulating the relations and interactions between individuals, organizations or groups [3].

With the usage of the stem cell products in health technologies, its market is poised to grow at a rate of 30\% from 2010 to 2012 and is projected to be around 1.2 billion dollar by 2012 and expected to reach around 16 billion dollar in 2017 (The Economic Times, Dec, 2012). One more estimation before that was that, the global market size for stem cell therapy in 2006 was estimated to be US $\$ 26$ billion and is projected to reach US $\$ 96$ billion by 2015 (Business Standard, 2008). Research in the United States, European Union and Asia is moving apace with increasing level of government support (UKSCI report, 2005). Indian stem cells market is growing at a rate of 15 percent per annum and is expected to hit US $\$ 540$ million by the year 2010 (Express Pharma, 2007), but still it is not in such a good command. India has not a good position in the global stem cell market as it is offering important and cost effective treatments in health systems in comparison to developed countries [21]. Freeman's book 'Unemployment and Technical Innovation', one of the first studies to apply a system approach to the role of innovation in long-run economic and social change, appeared in 1982 (Freeman, Clark and Soete, 1982). Stem cell treatment is very costly and other socio-economic issues are related to it like whether it would be safe or not. Even when controversies are on a high, the Department of Biotechnology (DBT), Government of India, has allocated $\$ 650,000$ (Rs 3 crore) in the last five years towards basic and applied research in stem cell technology. The Indian Council of Medical Research and the DBT had already announced the guidelines for stem cell research and therapy in 2007 , but India is yet to formulate norms for stem cell banking and storage procedures [22].

As the stem cell treatment is totally new and different from the other health treatment technologies, it is considered as radical innovation. Radical Innovations are fundamental changes that represent revolutionary changes in technology. They represent clear departures from existing practice. Dewar argue that a theoretical model of innovation should consider three kinds of variables: (a) the distribution of knowledge-the depth and diversity of knowledge 
and extent of exposure to information obtained from external sources; (b) attitudes of the organisation's management-the value they place on change; and (c) organisational structure-effects of the centralisation upon adoption behaviour [23]. The stem cell banking in India is yet to come under a regulatory framework. Moreover, Stem cell continues to be a promising field, which will rise to new levels the coming years [24].

There are significant numbers of laboratories, hospitals and firms that are active in this area and a few Universities have also taken initiatives. Stem cell research is a billion dollar industry which is going to increase and develop the economic in conditions of the nation. India is among the top ten countries in world in this field and making regulations on research on human embryonic stem cells to prepare for research within the country as well as possible international projects that might involve embryonic material from India. This predicts that India could emerge in this field. Reliance Life Science Research, Bombay, whose stem cell lines are approved by the US major source of embryonic stem cells as there is almost no public or religious debate on abortion, which is legal across India. This is a great benefit to India as compared to other nations that the ethical issues are not considered related to this research and also the higher authorities had proved successful in this duty by making the national bioethical panel [25]. A national bioethics panel, set up by India's department of biotechnology, has drafted new guidelines for human genomics research that also cover rules for the collection and use of embryonic stem cells. The panel said, "that scientists may harvest human embryos for research before day 14 of gestation with the informed consent of the donor". All projects would have to be approved by the national bioethics panel, and researchers would have to share any commercial benefits that emerge from embryonic stem cell lines with the donor. Senior officials say that the new rules draw on existing ethical guidelines from the Indian Council of Medical Research but that they will be enforceable. They have been approved by the law ministry and are intended to be legally binding. Two Indian research centers are among 10 worldwide named by the US National Institutes of Health as holding human stem cell lines that are eligible for US federal research funds.

\section{Indian SCR Organizations and Institutes}

Some technologies are implemented at the national level i.e. country vide; stem cell research treatment is also among such, not for a particular population but for whole. At national level health sector innovation system also functions under the formal bodies constituting of universities, firms, institutions. Pavitt worked on the differential concepts on how innovations operate across sectors and industries, appropriate conditions and the role that firm-level capabilities play for innovation and learning. Lundvall and Nelson have a major contribution in the NSI approach. Lundvall argued that two important dimensions "the structure of production" and "the institutional setup" jointly define the system of innovation [2]. Nelson emphasised more on empirical studies than theoretical development and focused on R and D systems of nations [3]. Nelson and Rosenberg addressed the organizations that promote the creation and dissemination of knowledge as the main source of innovation, i.e. those supporting $R$ and D [6]. Here in India the main organizations linked to this innovation system are DBT (Department of Biotechnology), DST (Department of Science and Technology), and ICMR (Indian Council of Medical Research). The hospitals, institutes and industries related to stem cell research in India are given as [26]:-

\section{Institutes, hospitals and industries involved in stem cell} research

\section{Embryonic stem cell research}

- National Institute for Research in Reproductive Health, Mumbai

- National Centre for Biological Sciences, Bangalore

- National Centre for Cell Science, Pune

- National Brain Research Centre, Manesar

- Rajiv Gandhi Centre for Biotechnology, Thiruvanthapuram

- Centre for Human Genetics, Bangalore

- Jawaharlal Nehru Centre for Advanced Scientific Research, Bangalore

Haematopoietic stem cells and bone marrow mononuclear cells

- Christian Medical College, Vellore

- Sanjay Gandhi Post Graduate Institute of Medical Sciences, Lucknow

- Post Graduate Institute of Medical Education and Research, Chandigarh

- Manipal Hospital, Bangalore

- All India Institute of Medical Sciences, New Delhi

- National Centre for Cell Science, Pune

- National Institute of Immunology, New Delhi

- Indian Institute of Science, Bangalore

- Indian Institute of Technology, Chennai

- Research \& Referral Hospital, New Delhi

Limbal stem cells

- L.V. Prasad Eye Institute, Hyderabad

- R. P. Centre, AIIMS, New Delhi

- Regional Institute of Ophthalmology, Kolkata

Neural stem cells

- National Brain Research Centre, Manesar

- National Institute of Mental Health and Neurosciences, Bangalore

- National Centre for Cell Science, Pune

- University of Hyderabad, Hyderabad

Mesenchymal stem cells

- Christian Medical College, Vellore

- Sanjay Gandhi Post Graduate Institute of Medical Sciences, Lucknow

- Manipal Hospital, Bangalore

Liver stem cells

- Centre for Liver Research and Diagnostics, Hyderabad

- Centre for DNA Fingerprinting and Diagnostics, Hyderabad 


\section{Pancreatic progenitor cells}

- National Institute of Nutrition, Hyderabad

- National Centre for Cell Science, Pune

\section{Cardiac stem cells}

- Sree Chitra Tirunal Institute for Medical Sciences and Technology, Thiruvananthapuram

Muscle stem cells

- Centre for Cellular and Molecular Biology, Hyderabad

Cancer stem cells

- Indian Institute of Science, Bangalore

CMC-DBT Centre for Stem cell research

- Christian Medical College, Vellore

Stem cell research facilities

- Postgraduate Institute of Medical Education and Research, Chandigarh

\section{Clean room facilities for stem}

- Sanjay Gandhi Post Graduate Institute of Cell Research Medical Sciences, Lucknow

- KEM Hospital, Mumbai

- L.V. Prasad Eye Institute, Hyderabad

Cord blood bank

- Reliance Life Sciences, Mumbai

- Life Cell, Chennai

\section{Stem Cell Treatment-Problems Gapping its Applications}

As discussed above about the stem cell research and its benefits in the field of health system, how useful it is in curing some serious diseases, there are also some problems related to its applications. Government and other authorities are providing huge funding for the research and development in this field. Scientists and researchers are also making good effort and progress in the health systems same in the stem cell research field. In fact, we can say that India is progressing as it ranks among the top ten nations in world in this field [27]. But the problem here is that if we are investing such large resources in this field, would it be successful or not, and challenge the problems if, posed by it. There are many problems which can obstruct its applications and the important ones are its affordability to the general public and whether people would trust or believe on it or not.

\section{Affordability as a major problem}

India holds a peculiar position in the existing world order. It is described as an underdeveloped, impoverished nation - at times even as third-world. It is also frequently touted as the next great hope for science; a country populated by engineers, mathematicians, and biologists - poised to develop the most advanced biotechnologies [28]. Progress is been made in every field especially in medical technologies.

Affordability means cure and treatments must be priced, so all citizens can afford and benefit from them, not just a wealthy few. This can be made possible only if government bodies will support it. This can be made possible by awaking people through its benefits and one time therapeutic application. It is costly but its single dosage marks off the other medicines which a patient has to use life time hence also avoiding the everyday money wastage [29]. Also the government has to make some policies to subsidize such useful application for the whole public in order to make healthy nation.

\section{Social ethics and safety problems related to SCR}

Most of the medical procedures have many risks, so it is crucial research field. In health system the stem cell therapeutic way of treatment is very critical. The socio-ethical problem related to this treatment is about the views of general public towards it. Both literate and illiterate people have different negative or positive views concerned to this treatment. Literate people think about its side effects or other risks because of injecting these cells in the body can harm the immune system or would become antigenic to the immune functions of body. Different religions give different status to the early human embryo in different ways. For example, the Roman Catholic, Orthodox and conservative Protestant-Churches points out that the embryo has the status of a human from conception and no embryo research should be permitted. Judaism and Islam accentuate the importance of helping others and argue that the embryo does not have full human status before 40 days, so both these religions permit some research on embryos [29]. Hence it is still a debate in order to understand whether the morality of human embryo gets deceased or not. People lacking the scientific knowledge are most superstitious about these facts, from where these cells have been derived, whether they are safe or not and the most problem is that people are first of all not aware about the new innovations in the medical fields. Stem cell research firstly needs isolation of these cells, as soon as the cells leave body they may be subjected to a number of manipulations that could change the characteristics of the cells. If they are grown in culture (a process called expansion), the cells may lose the normal mechanisms that control growth or may lose the ability to specialize into the cell types you need. The cells may become contaminated with bacteria, viruses or other pathogens that could cause disease. The procedure to either remove or inject the cells also carries risk, from introducing an infection to damaging the tissue into which they are injected. So this should be carried with intensive care in order to make it safe for the public.

\section{Conclusion}

Health sectorial system reveals everyday with new technologies and innovations which help in defending the diseases and promising the better health. Stem cell research and its application is a radical innovation in the biomedical field providing treatment to various diseases. It is beneficial because first it eradicates the diseases making a patient disease free and second great benefit is that it is only dosed once and not used as medicines which are taken regularly. It can provide treatment of such diseases which are very serious, so it needs enthusiastic support to progress. India as a developing country is making a sky high progress in this field as compared to other such countries. The organizations and other government authorities are also working tightly, but making to it too developed it needs proper and valuable funding. Related to its applications sometimes it poses ethical problems which should be handled in such a way that it may not cause any obstruction in its development and progress. People should be made aware of such applications and government should help in providing such benefits by subsidizing them. 
Citation: Alaie SA (2015) Stem Cell Treatment as Innovation in Sustaining Socio-Economic Condition in Health Care Sector in India. J Stem Cell Res Ther 5: 269. doi:10.4172/2157-7633.1000269

Page 7 of 7

\section{References}

1. Schumpeter JA (1934) The Theory of Economic Development. Harvard University Press, Cambridge.

2. Lundvall L (1992) National innovation systems: towards a theory of innovation and interactive learning. Pinter, London.

3. Edquist C (2004) Systems of innovation perspectives and challenges. Oxford Handbook of Innovation, London.

4. Breschi S, Malerba F (1997) Sectoral systems of innovation: technological regimes, Schumpeterian dynamics and spatial boundaries. Pinter, London.

5. Carlsson B, Jacobsson S (1997) Diversity creation and technological systems: a technology policy perspective. Pinter, London.

6. Arrow K (1962) Economic Welfare and the Allocation of Resources for Innovation. Princeton University Press, Princeton.

7. ICMR-DBT Guidelines for Stem Cell Research

8. Berrios GE (1991) Alzheimer's disease: A Conceptual History. Int J Geriat Psychiatry 5: 355-365.

9. Weissman IL, Anderson DJ, Gage F (2001) Stem and progenitor cells: origins, phenotypes, lineage commitments, and transdifferentiatons. Annu Rev Cell Dev Biol 17: 387-403. [PubMed]

10. Greenwood HL (2006) Regenerative medicine: new opportunities for developing countries. Int J Biotechnol 8: 60-77.

11. Hug K (2006) Therapeutic perspectives of human embryonic stem cell research versus the moral status of a human embryo - does one have to be compromised for the other? Medicina (Kaunas) 42: 107-114. [PubMed]

12. Schekman R, Shultz M (2006) Stem Cell Research: Opportunities and Challenges. Bulletin of the American Academy of Arts and Sciences 59: 17-22.

13. Takahashi K, Yamanaka S (2006) Induction of pluripotent stem cells from mouse embryonic and adult fibroblast cultures by defined factors. Cell 126: 663-676. [PubMed]

14. Hanna J, Wernig M, Markoulaki S, Sun CW, Meissner A, et al. (2007) Treatment of sickle cell anaemia mouse model with iPS cells generated from autologous skin. Science 318: 1920-1923. [PubMed]
15. Colman A Dreesen O (2009) Pluripotent stem cells and disease modeling. Cell Stem Cell 5: 244-247. [PubMed]

16. Herteis A (2008) Information technology, stem cells, and poverty: modernity and the social impact of technological innovation in India.

17. Zerhoun E (2003) Embryonic stem cells. Stem Cell Programs. Science 300: 911-912. [PubMed]

18. Saha K, Jaenisch R (2009) Technical challenges in using human induced pluripotent stem cells to model disease. Cell Stem Cell 5: 584-595. [PubMed]

19. Rajarathna (2010) Advancements in stem cell research: An Indian perspectiveII. Ann Neurosci 17: 110-112. [PubMed]

20. Healthcare: Eleventh Five Year Plan (2007-2012). Report on health Systems Research, Biomedical Research and Development, and Regulations of Drugs and therapeutics.

21. Stem Cell Research in India (2012) Report: Market Research Reports.

22. Ramalingaswami V (1984) National Health Research Policy: Annual Report (2011-2012). Department of Health Research. Science and Public Health-The Indian Paradox.

23. NICRM, stem cell needs regulatory pathway report.

24. ICMR-DBT Guidelines for Stem Cell Research (2012).

25. Tiwari SS, Desai PN (2011) Stem cell innovation system in India: emerging scenario and future challenges. World journal of science, technology and sustainable development.

26. Sharma A (2006) Stem Cell Research in India: Emerging Scenario and Policy Concerns.

27. Sharma A (2006) Stem cell research in India: Emerging scenario and policy concerns. Asian Biotechnology and Development Review 8: 43-53.

28. Simpson JP (2006) Affordability, accessibility and accountability in California stem cell research, The Foundation for Taxpayer and Consumer Rights.

29. Mudur G (2001) India to tighten rules on human embryonic stem cells research BMJ 323: 530. [PubMed] 